\title{
Optimizing B2B transactions using the marketplace competitive analyzer
}

\author{
Andrés L. Medaglia $^{1 *}$, Marc-david Cohen ${ }^{2}$, Daniel Castro-Lacouture ${ }^{3}$ \\ 1 Departamento de Ingeniería Industrial, Centro de Optimización y Probabilidad Aplicada, \\ Universidad de Los Andes, A.A.4976, Bogotá, Colombia \\ 2 Fair Isaac Corporation, 200 Smith Ranch Road, San Rafael, CA 94903, U.S.A. \\ ${ }^{3}$ Department of Civil Engineering, Ohio University, Athens, OH 45701, U.S.A.
}

(Received June 20 2006,Accept July 29 2006)

\begin{abstract}
In a business-to-business (B2B) environment, most if not every large company interacts with suppliers, customers, and competitors on one or more Net markets, connecting to both ends of the supply chain, the supplier side and the customer side. To support purchasing agents, analysts, and managers in evaluating their purchasing decisions, a new analytical tool is presented, the Marketplace Competitive Analyzer (MCA). The MCA is a component of a total supply chain solution. It is supportive of the supplier relationship management (SRM) concept and extends its functionality into electronic marketplaces. In this way, the MCA solution expands the SRM concept into the B2B world of online exchanges. MCA is also of value in the selling end of the supply chain, though this paper mainly focuses on the buying end of the supply chain. MCA analyzes the past transactions for a given commodity in a Net market using Data Envelopment Analysis (DEA), a nonparametric efficiency analysis technique based on linear optimization. DEA and MCA are used to analyze the efficiency of each buy position in the Net market. This helps the decision maker discover possible tradeoffs while considering the terms of the purchase, such as price, lead time, quality and quantity. MCA can be used to design optimal spot buy bids in the supplier end of the chain, so that the procurement activities are better supported. As a result, MCA helps the analyst to design an efficient and advantageous spot buy offer.
\end{abstract}

Keywords: net market, B2B, spot buys, data envelopment analysis, supply chain optimization

\section{Introduction}

Eventually, every large company will operate in the new B2B Internet exchange, where companies interact with suppliers, customers, and competitors on one or more Net markets. These Net markets (also known as online exchanges, business-to-business portals, trading hubs, trading networks, and e-marketplaces) have connections to both ends of the supply chain, the supplier side and the customer side. Fig. 1 shows a supply chain and its interaction with Net markets and traditional suppliers and customers.

In general, purchasing agents, analysts and managers are involved in two types of buying: strategic and spot. To support purchasing in evaluating spot buys in Net markets, a new analytical tool called the Marketplace Competitive Analyzer (MCA) has been developed. The MCA is a component of a total supply chain solution. It is supportive of the Supplier Relationship Management (SRM) concept and extends its functionality into electronic marketplaces. In this way, the MCA solution expands the SRM concept into the B2B world of online exchanges. The SRM concept promises a holistic approach to procurement that tightly integrates procurement decisions with the demands of the supply chain in a financially responsible way. It is important to note that MCA is also of value in the selling end of the supply chain. However, this paper focuses primarily on the buying end of the supply chain.

\footnotetext{
* Corresponding author. Tel.: +57-1-3394949 ext. 3877.

E-mail address: amedagli@uniandes.edu.co.
} 

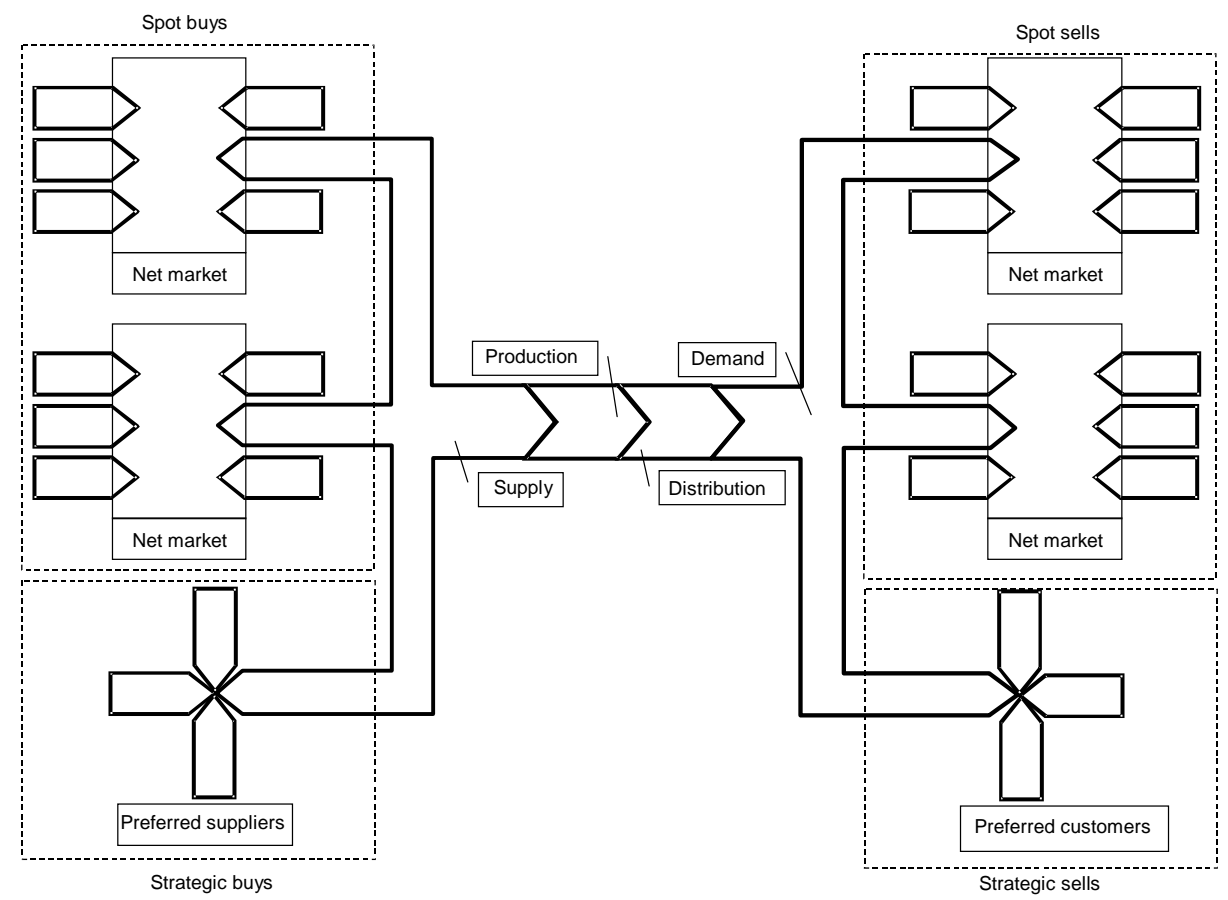

Fig. 1. Interactions of the supply chain with B2B Net markets and traditional suppliers and customers

MCA analyzes the past transactions for a given commodity in a Net market using Data Envelopment Analysis (DEA) ${ }^{[3]}$, a non-parametric efficiency analysis technique based on linear optimization. Using DEA, MCA analyzes the efficiency of each buy position in the Net market. This helps the decision maker discover possible tradeoffs while considering the terms of the purchase, such as price, lead time, quality and quantity. As a result, MCA helps the analyst to design an efficient and advantageous spot buy offer. Similarly, at the other end of the supply chain, it could help a purchasing analyst to design an efficient spot sell offer.

\section{Background}

Buying and sellers in an e-Business environment are continuously looking for aids that allow them to make an advantageous transaction. The dynamic nature of Business-to-Business exchanges, now characterized by dynamic pricing schemes and other agent-based architectures, is composed of information that is constantly changing, thus leaving decision makers with less certainty regarding the conditions of future transactions. The use of shopping aids has an impact on subjects' perceptions about online shopping, thus reducing search efforts and increasing confidence in purchase decisions ${ }^{[10]}$. Shopping aids are designed to enable individuals to compare offers more objectively, efficiently and accurately ${ }^{[4]}$. Price is one of the factors that influence the decision for an individual to consider an offer. Besides, there is a tradeoff between price and the search costs for price information. The higher the search costs of searching for price information, the lower the price sensitivity. Therefore, the sellers can maintain prices substantially above their marginal costs, thus resulting in market inefficiencies ${ }^{[8]}$.

Several models have been developed to find the implications for an e-tailer's pricing strategy with regards to the effect of prices and price satisfaction. Results have shown that e-tailers have higher levels of price satisfaction from providing a satisfying ordering experience ${ }^{[1]}$. New pricing strategies have emerged during recent years, dynamic pricing being one of the most dominant ones. This category includes the dynamic updating of posted prices and auctions. The effects on customers of dynamic pricing have been assessed, thus studying the motivators of differences between physical and virtual value chains ${ }^{[6]}$.

The proliferation of auctions on the web and their dynamic nature has provided a fertile ground for the development of intelligent trading agents. An agent can monitor and participate in the market continuously, make complex decisions in real time and have the autonomy to make decisions that commit its user to future 
actions ${ }^{[11]}$. Agent-based electronic commerce systems have been developed with the intention of testing life spans, semi-autonomy, maintenance of each actor's profile through the personalization of the agents involved, ability to refine some of the customer's purchase criteria and to handle incomplete or inconsistent information [7]. Another approach evaluates an algorithm that autonomous software agents can employ to submit bids in continuous double auctions ${ }^{[5]}$. This type of auction permits trading at any time in a trading period, thus allowing buyers and sellers to continuously update their bids.

Transactions executed over an exchange are rich in data about buyers and sellers and their activities, individually and in the aggregate, and therefore about the economics of the whole industry in which the exchange operates. The Internet enables the accumulation and analysis of minute slices and dices of data never before possible with any other technology in business-to-business commerce. All of the data on buyers, sellers, and transactions that is aggregated at a B2B Internet exchange is an asset that may be monetized. Data aggregation will be a very viable, long term revenue opportunity for exchanges, we believe. An exchange may collect data on every buyer, seller and transaction, then combine and recombine the information in endless standardized and customized ways, for buyers, sellers and others to purchase ${ }^{[9]}$.

\section{Business problem}

Typically, a purchasing agent in a Net marketplace is faced with the problem of defining an advantageous spot buy offer. For instance, suppose that in a paper Net market such as PaperFiber.com, an agent needs to bid on paper to be used in copy machines. Before submitting the bid to the exchange, the agent needs to fully understand the possible tradeoffs between quantity, delivery time, price to be paid, and quality, among others. By using MCA these are some of the questions the agent can answer:

- How much should I offer in my bid?

- How much material should I get in order to make an efficient offer?

- How many more units should I get for the same price if I am willing to wait longer?

- How can I fine tune my bid to make it competitive?

Efficiency in MCA could be better understood in the classical engineering sense, as a generalized ratio between outputs and inputs. In few words, a spot buy is efficient if it gets more outputs (e.g., quantity and quality) for fewer inputs (e.g., lead time and price).

\section{The marketplace competitive analyzer model}

\subsection{The model}

MCA is based on the additive DEA model ${ }^{[2]}$. Thus, it requires solving a sequence of linear programs, one per each past transaction of interest in the Net marketplace. The mathematical formulation of the underlying MCA model follows.

Let $\mathcal{J}$ be the set of decision making units (DMUs). In the Net marketplace context of MCA, these DMUs are the past transactions. The total number of transactions is $n=|\mathcal{J}|$. Let $\mathcal{J}$ and $\mathcal{R}$ be the set of factors in a transaction considered to be inputs and outputs, respectively. The total number of inputs and outputs is $m=|\mathcal{J}|$ and $s=|\mathcal{R}|$, respectively. The input data for the MCA model is determined by $x_{i j}$, the amount of input $i$ in transaction $j$; and $y_{r j}$, the amount of output $r$ in transaction $j$. The decision variables are $\lambda_{j}$, the efficient front projection multiplier for transaction $j ; s_{r}^{+}$, the efficient front slack for output $r$; and $s_{i}^{-}$, the efficient front slack for input $i$. For each transaction $j^{\prime}=1, \cdots, n$, the following linear optimization model is solved:

$$
\min _{\vec{\lambda}, s^{+}, s^{-}} z_{j^{\prime}}=-\sum_{r \in \mathcal{R}} s_{r}^{+}-\sum_{i \in \mathcal{J}} s_{i}^{-}
$$

subject to 


$$
\begin{gathered}
\sum_{j \in \mathcal{J}} y_{r j} \lambda_{j}-s_{r}^{+}=y_{r j^{\prime}}, r \in \mathcal{R} \\
\sum_{j \in \mathcal{J}} x_{i j} \lambda_{j}+s_{i}^{-}=\quad x_{i j^{\prime}}, i \in \mathcal{J} \\
\sum_{j \in \mathcal{J}} \lambda_{j}=1 \\
\lambda_{j} \geq 0, j \in \mathcal{J} \\
s_{r}^{+} \geq 0, r \in \mathcal{R} \\
s_{i}^{-} \geq 0, i \in \mathcal{J}
\end{gathered}
$$

The next section shows how MCA model can be used depending on the interested agent in the Net marketplace.

\subsection{Marketing targets}

MCA is a supply chain tool that can expand the analytical capabilities of three different entities: sellers, buyers, and the Net marketplace. The following figures show where MCA fits in the general landscape shown in Fig.1.

In Fig. 2, MCA is owned by the buyer, and serves as an analytical tool for the purchasing analyst as it has been previously explained.

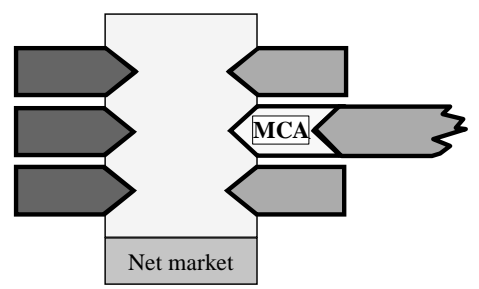

Fig. 2. MCA as an analytical tool for the buyer

In Fig. 3, MCA is owned by the seller. Even though it has not been discussed, MCA can be used to negotiate better sell offers in a Net market.

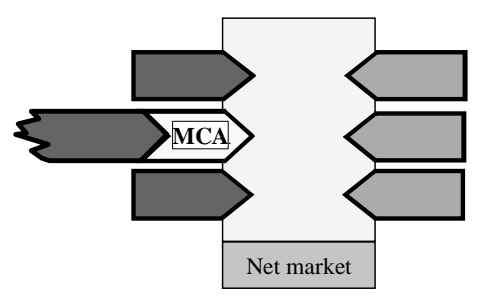

Fig. 3. MCA as an analytical tool for the seller

In Fig. 4, MCA is owned by the Net market. The exchange collects and owns valuable information on the transactions made therein. Under this framework, the subscribers of the exchange (sellers and buyers) may be willing to pay a fee to use this value-added analytical service. MCA may use the quantitative data from the transactions, without revealing the identity of the parties involved. 


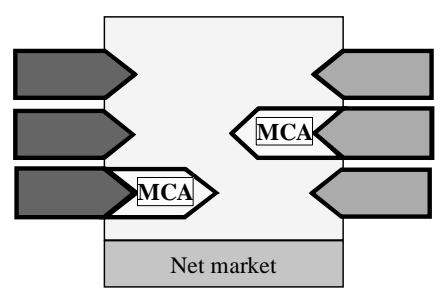

Fig. 4. MCA as an analytical tool for the Net market

\section{Computational example}

\subsection{Input data}

The data required by MCA are the completed transactions in the Net market, understood as the previous matches between buyers and sellers. The data comes directly from the Net market or from the purchasing agent who keeps track of the activity on a given exchange. Tab. 5.1 contains sample data from a paper exchange. Each row in the table contains information on a purchase transaction for a given commodity, for instance, paper for copy machines.

\begin{tabular}{ccccccccc}
\hline Date & Buyer & $\begin{array}{c}\text { Trans. } \\
\text { ID }\end{array}$ & $\begin{array}{c}\text { Paid } \\
(\times 10000)\end{array}$ & $\begin{array}{c}\text { Lead } \\
\text { Time } \\
(\text { days })\end{array}$ & $\begin{array}{c}\text { Quantity } \\
(\text { short tons })\end{array}$ & $\begin{array}{c}\text { Weight } \\
\left(\text { grams } / \mathrm{m}^{2}\right)\end{array}$ & $\begin{array}{c}\text { Caliper } \\
(\mathrm{pt})\end{array}$ & $\begin{array}{c}\text { Quality } \\
0.80\end{array}$ \\
\hline $5 / 8 / 00$ & Paper Mill Co. & DMU-001 & 36.08 & 20 & 44 & 20 & 4 & 0.80 \\
$7 / 30 / 99$ & Snow Paper Inc. & DMU-002 & 8.234 & 34 & 17 & 18 & 5 & 0.87 \\
$7 / 11 / 99$ & Paper Supply Co. & DMU-003 & 15.024 & 27 & 20 & 19 & 3 & 0.75 \\
$4 / 14 / 99$ & Paper Mill Co. & DMU-004 & 11.873 & 30 & 12 & 20 & 6 & 0.93 \\
$4 / 14 / 00$ & Willy John and Sons & DMU-005 & 2.345 & 10 & 3 & 16 & 2 & 0.75 \\
$3 / 27 / 98$ & Publishers Unlimited & DMU-006 & 36.883 & 18 & 40 & 21 & 3 & 0.94 \\
$2 / 23 / 99$ & Colombian Books & DMU-007 & 15.882 & 25 & 20 & 22 & 4 & 0.77 \\
$8 / 28 / 00$ & Oma Publishers & DMU-008 & 22.002 & 14 & 26 & 20 & 3 & 0.83 \\
$5 / 27 / 99$ & Books and Books & DMU-009 & 2.938 & 17 & 4 & 22 & 3 & 0.82 \\
$8 / 27 / 99$ & Willy John and Sons & DMU-010 & 37.453 & 21 & 47 & 22 & 7 & 0.73 \\
$2 / 20 / 98$ & McWiley-Hall Inc. & DMU-011 & 5.927 & 24 & 7 & 20 & 4 & 0.85 \\
$6 / 29 / 99$ & Paper Mill Co. & DMU-012 & 17.283 & 23 & 21 & 18 & 5 & 0.88 \\
$5 / 17 / 99$ & Tayrona Paper Co. & DMU-013 & 23.021 & 19 & 36 & 15 & 4 & 0.82 \\
\hline
\end{tabular}

Table 1. Sample data for a paper net market

\subsection{Reports}

The MCA was implemented in the SAS language. Fig. 5 shows the SAS code that defines the input data shown in Tab. 5.1.

To illustrate the reports available with MCA, data from Tab. 5.1 is used. First, the simple, but illustrative case is considered in which the amount paid as input and the quantity as output are analyzed. After running the MCA model (see Fig. 6 and 7), the efficient front shown in Fig. 8 can be obtained. The transactions with Transaction ID of DMU-005, DMU-002, DMU-013, and DMU-010 are efficient and are labeled with stars. They define an envelope in which all the transactions below it are called inefficient. In other words, the efficient transactions serve as a reference set of best buy offers. Suppose that the buyer is thinking of making a bid similar to the transaction DMU-006, this is, paying $\$ 36,883$ for 40 short tons. Fig. 9 , shows the recommendation made by MCA. If the buyer is willing to make an efficient bid, as much as $\$ 28,969$ must be paid for 40 short tons of paper. After this simple analysis of all the previous transactions made in the Net market, the buyer may want to rethink the offer. Tab. 5.2 describes the relationship between efficiency and ratios after running the MCA model. 


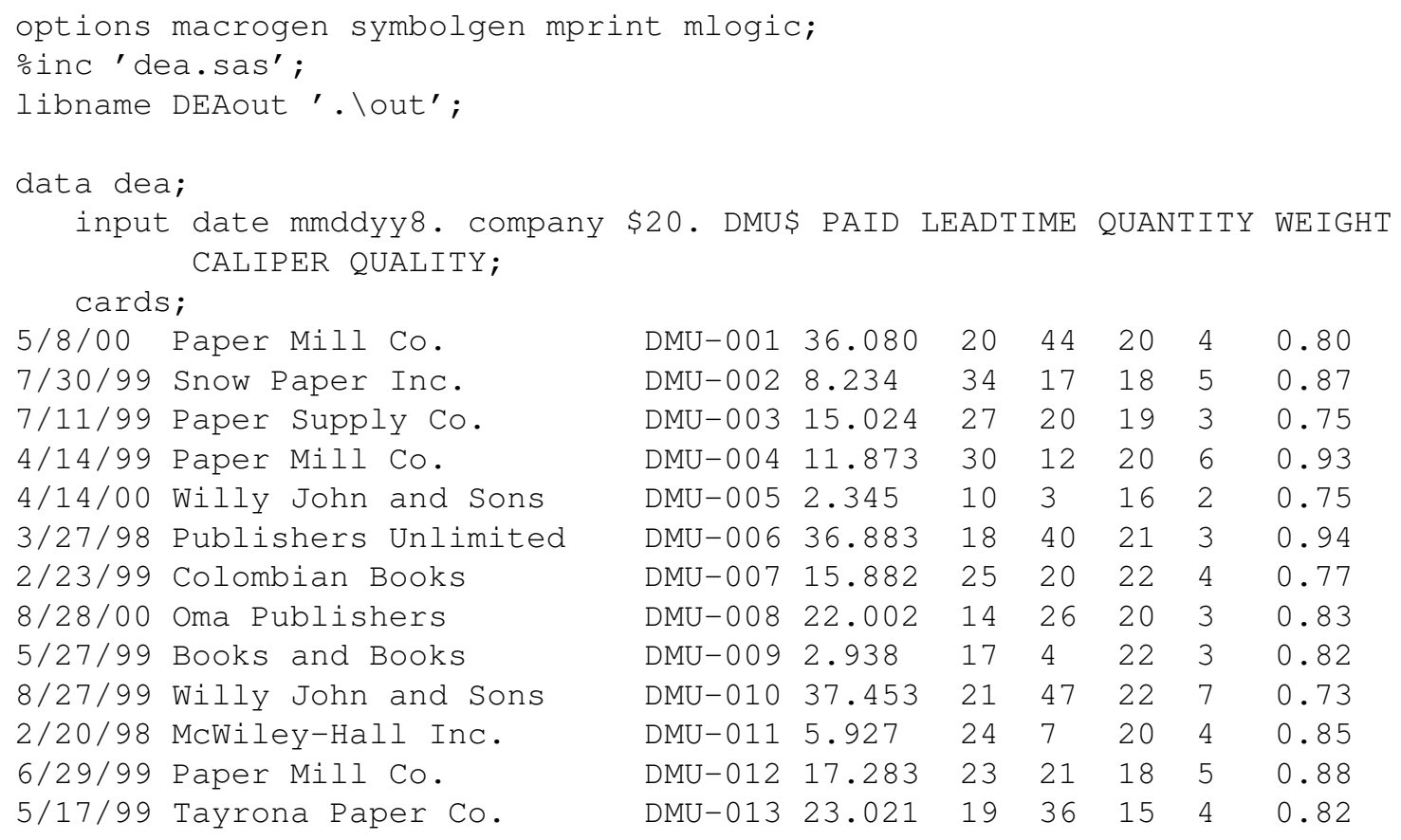

$\begin{array}{lllllll}\text { DMU-001 } & 36.080 & 20 & 44 & 20 & 4 & 0.80 \\ \text { DMU-002 } & 8.234 & 34 & 17 & 18 & 5 & 0.87 \\ \text { DMU-003 } & 15.024 & 27 & 20 & 19 & 3 & 0.75 \\ \text { DMU-004 } & 11.873 & 30 & 12 & 20 & 6 & 0.93 \\ \text { DMU-005 } & 2.345 & 10 & 3 & 16 & 2 & 0.75 \\ \text { DMU-006 } & 36.883 & 18 & 40 & 21 & 3 & 0.94 \\ \text { DMU-007 } & 15.882 & 25 & 20 & 22 & 4 & 0.77 \\ \text { DMU-008 } & 22.002 & 14 & 26 & 20 & 3 & 0.83 \\ \text { DMU-009 } & 2.938 & 17 & 4 & 22 & 3 & 0.82 \\ \text { DMU-010 } & 37.453 & 21 & 47 & 22 & 7 & 0.73 \\ \text { DMU-011 } & 5.927 & 24 & 7 & 20 & 4 & 0.85 \\ \text { DMU-012 } & 17.283 & 23 & 21 & 18 & 5 & 0.88 \\ \text { DMU-013 } & 23.021 & 19 & 36 & 15 & 4 & 0.82\end{array}$

Fig. 5. SAS code for defining input data for MCA

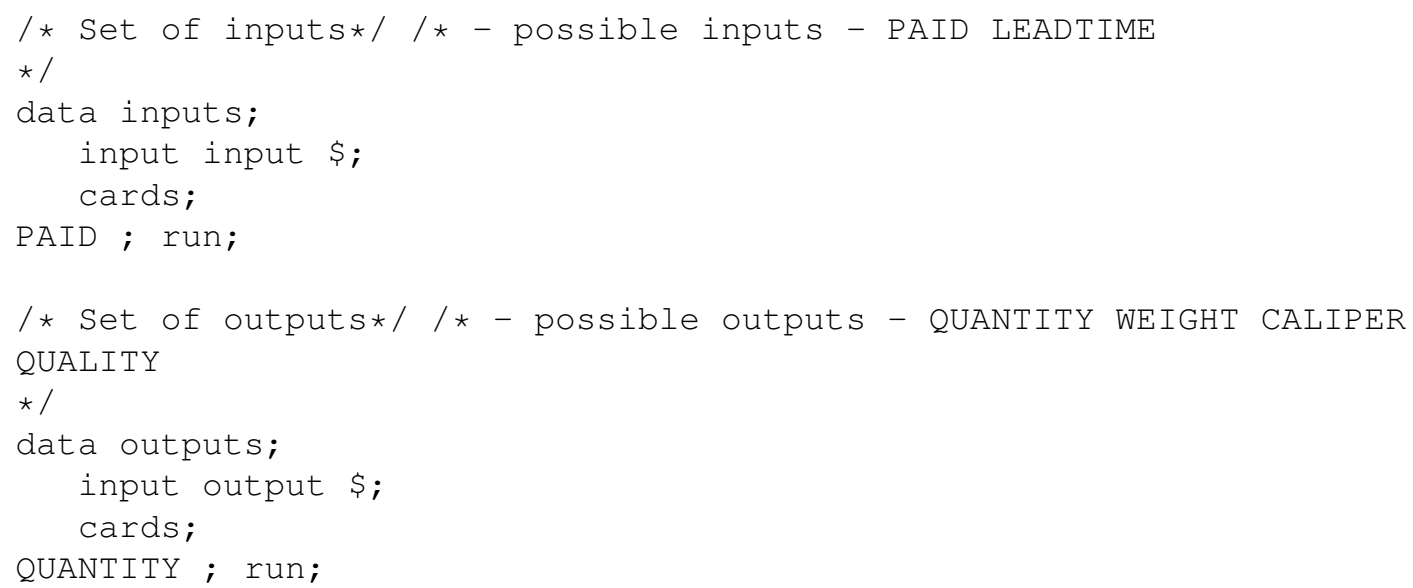

Fig. 6. SAS code for defining inputs and outputs for the single input-output scenario

To see MCA at its full potential, an MCA model is analyzed with two inputs, amount paid and lead time, and two outputs, quantity and quality (see Fig. 10 and 11). The rationale behind this model is that if more is to be paid or deliver time is to be longer, then either more quantity or better quality is to be received (or perhaps both). In this case, an efficient front is very difficult to visualize, but MCA still can help the purchasing analyst with the design of the spot purchase offer. A quick exploration of the output of MCA suggests that under this new model, transaction DMU-007 is not efficient (under the MCA model, DMU-003, DMU-007, DMU-011, and DMU-013, are considered inefficient). If the analyst is planning to make a spot buy offer similar to transaction DMU-007, the MCA output in Fig. 12 tells the analyst that there is room to improve this bid. For the amount of money that is being offered $(\$ 15,882)$ the company should be asking for a 


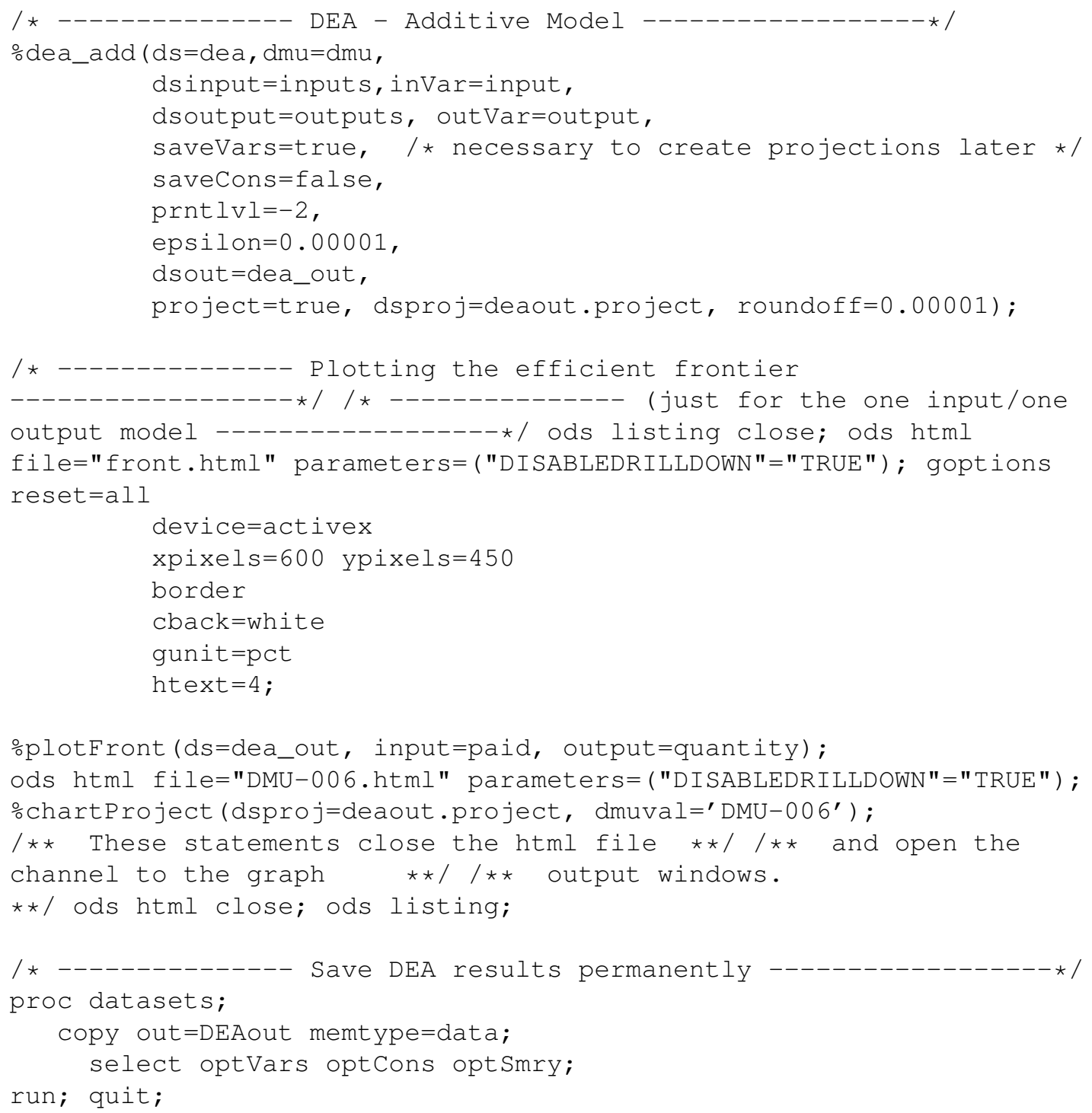

Fig. 7. SAS code for defining the model and generating the efficient front and projection reports for the single inputoutput scenario

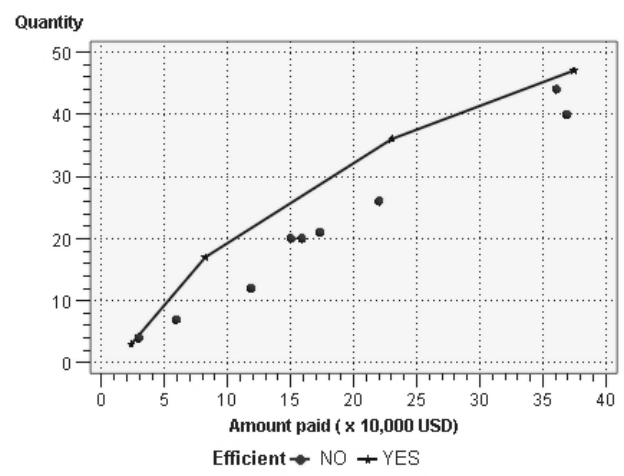

Fig. 8. Efficient front generated by MCA 


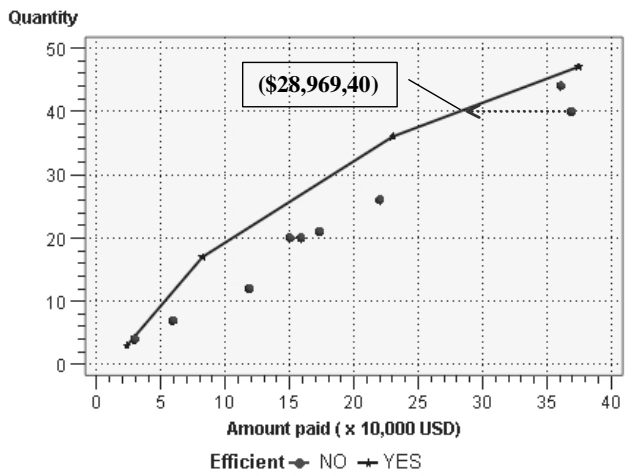

Fig. 9. Projecting an inefficient transaction onto the efficient front

\begin{tabular}{ccc}
\hline Transaction ID & Units/\$ & Efficient? \\
\hline DMU-002 & 2.06 & Yes \\
DMU-013 & 1.56 & Yes \\
DMU-009 & 1.36 & No \\
DMU-003 & 1.33 & No \\
DMU-005 & 1.28 & Yes \\
DMU-007 & 1.26 & No \\
DMU-010 & 1.25 & Yes \\
DMU-001 & 1.22 & No \\
DMU-012 & 1.22 & No \\
DMU-008 & 1.18 & No \\
DMU-011 & 1.18 & No \\
DMU-006 & 1.08 & No \\
DMU-004 & 1.01 & No \\
\hline
\end{tabular}

Table 2. Relation between efficiency and ratios

shorter lead time (about 9 less days), higher quality (an improvement of about 2.5\%), and more paper (about 4.6 short tons). Even though this might not be possible at the current market conditions, the analyst could use this information to fine tune his offer or negotiate a better deal.

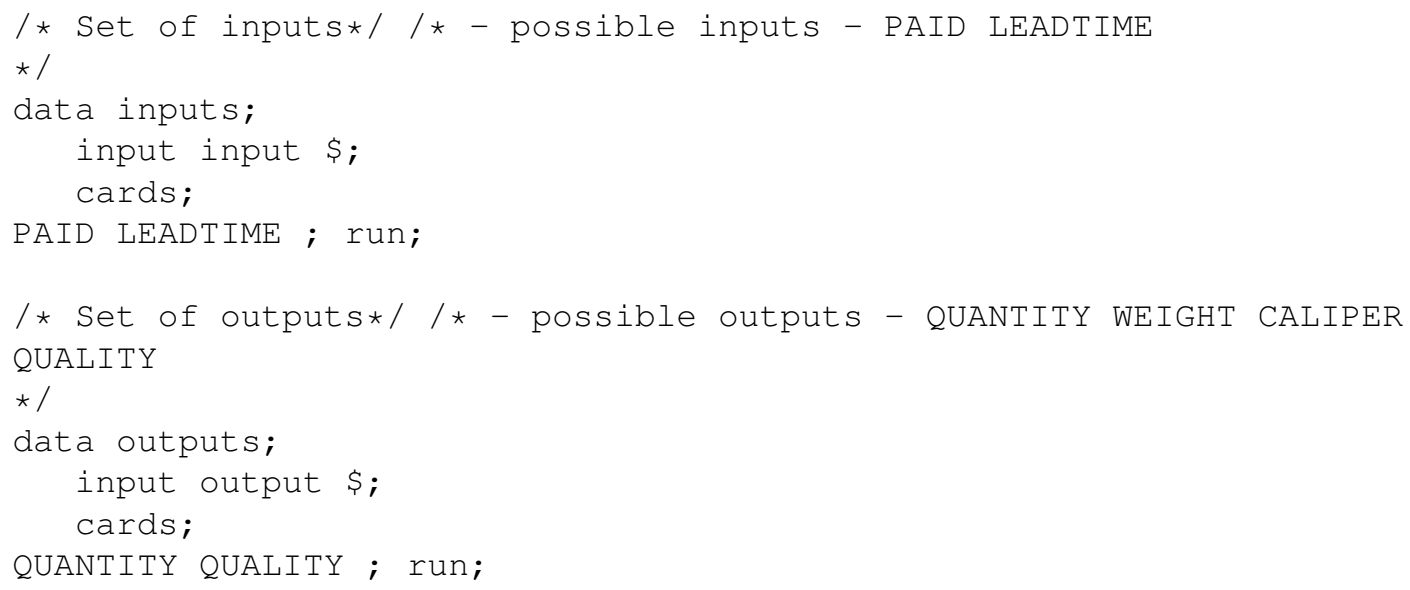

Fig. 10. SAS code for defining inputs and outputs for the multiple input-output scenario 


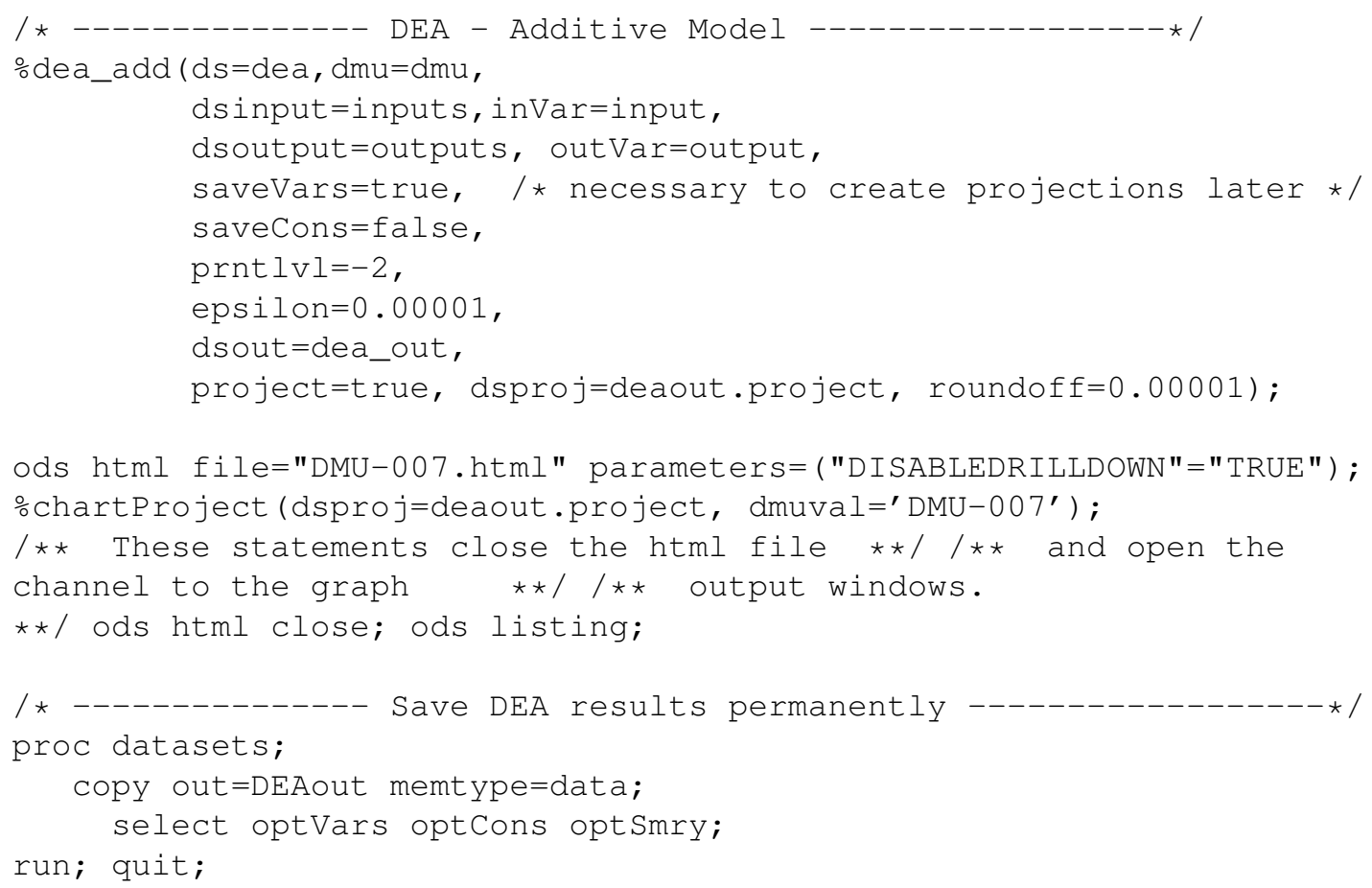

Fig. 11. SAS code for defining the model and projection reports for the multiple input-output scenario

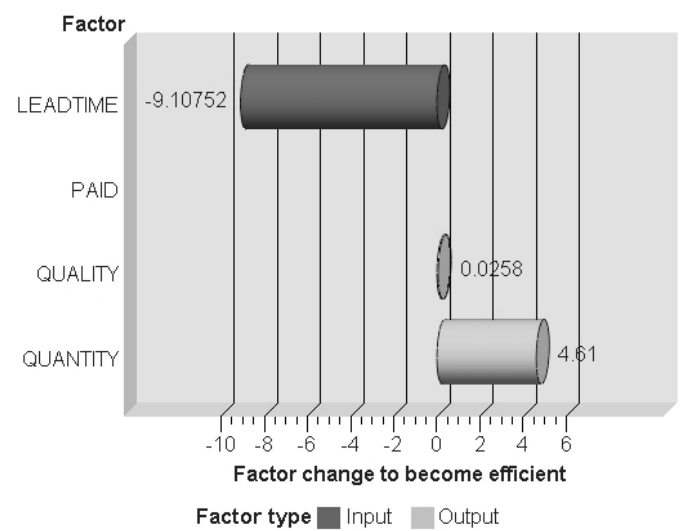

Fig. 12. Improving the spot buy offer based on DMU-007 


\section{Conclusions}

MCA is a new tool based on DEA that supports purchasing agents, analysts and managers with the evaluation of their purchasing decisions. MCA can be strategically used in both ends of the supply chain while interacting with highly competitive Net markets. In this paper it was shown how MCA can be used to design optimally spot buy bids in the supplier end of the chain, so that the procurement activities are better supported. There are several ways to target MCA: to a buyer, a seller, or a Net market, itself. Illustrative examples developed with SAS software have been shown.

\section{References}

[1] Y. Cao, T. Gruca, B. Klemz. Internet pricing, price satisfaction, and customer satisfaction. International Journal of Electronic Commerce, 2003, 8(2): 31-50.

[2] A. Charnes, W. W. Cooper, B. Golany, L. M. Seiford, J. Stutz. Foundation of data envelopment analysis for paretokoopmans efficient empirical production functions. Journal of Econometrics, 1985, 30(1/2): 91-107.

[3] W. W. Cooper, L. M. Seiford, K. Tone. Data Envelopment Analysis: A Comprehensive Text with Models, Applications, References and DEA-Solver Software. Kluwer Academic Publishers, Boston, 2000.

[4] G. Haubl, V. Trifts. Consumer decision making in online shopping environments: The effects of interactive decision aids. Marketing Science, 2000, 19(1): 4-21.

[5] M. He, H. Leung, N. Jennings. A fuzzy-logic based bidding strategy for autonomous agents in continuous double auctions. IEEE Transactions on Knowledge and Data Engineering, 2003, 15(6): 1345-1363.

[6] P. Kannan, P. Kopalle. Dynamic pricing on the internet: Importance and implications for consumer behavior. International Journal of Electronic Commerce, 2001, 5(3): 63-83.

[7] N. Karacapilidis, P. Moraitis. Building an agent-mediated electronic commerce system with decision analysis features. Decision Support Systems, 2001, 32: 53-69.

[8] H. Riquelme. An empirical review of price behaviour on the internet. Electronic Markets, 2001, 11(4): $263-272$.

[9] L. Trepp. Valuing the New Industrial Model: B2B Internet Exchanges. Philadelphia: Electronic Market Center, Inc., 2000. Available at http: / / www . nmm. com/documents/B2BExch.pdf.

[10] L. Vijayasararthy, J. M. Jones. Do internet shopping aids make a difference? an empirical investigation. Electronic Markets, 2001, 11(1): 75-83.

[11] P. Wurman. Dynamic pricing in the virtual marketplace. IEEE Internet Computing, 2001, 5(2): 36-42. 